\title{
Modelling and simulation of Concentrated Solar Power Plant in Ber'Alganam area (Azzawia-Libya)
}

\author{
Ibrahim A. Abuashe ${ }^{{ }_{1}}$, Essaied M. Shuia ${ }^{2}$ and Hajer I. Aljermi ${ }^{3}$ \\ ${ }^{1}$ Aeronautical engineering, Faculty of engineering, Azzawia University, Azzawia-Libya \\ ${ }^{2}$ Faculty of engineering, Subratha University, Subratha-Libya \\ ${ }^{3}$ Physical science, faculty of science, Azzawia University, Azzawia Libya

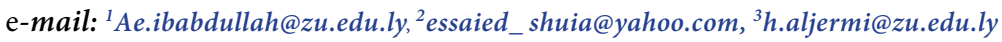

\begin{abstract}
This paper aims to conduct modeling and simulation of a Concentrated Solar Power (CSP) Plant in Ber'Alganam area (Azzawia-Libya). The thermal analysis of the solar power plant was carried out to identify its characteristics and present the monthly power curves according to measured solar radiation and meteorological data of Ber'Alganam (Azzawia-Libya). The mathematical model of the plant was based on energy balance of each component used to develop the simulation tool using Matlab software. The simulation tool can be used to simulate the solar plant and achieve desired plots and results. Among many techniques used in the field of solar power generation, the Concentrated Solar Power (CSP) technology using Parabolic Trough Collector (PTC) or (PT) has been selected. As a sample case, a $30 \mathrm{MW}$ CSP plant was proposed to present the hourly performance and productivity through entire year. The study offered a description of two more technologies; thermal energy storage (TES) and backup boiler in order to enhance and stabilize the CSP plant and the continuous production throughout daytime and estimate the amount of fuel needed for this issue, the results shows, the annual power output by both solar source, TES system, and the backup boiler are $91513,318.36$, and $4690.45 \mathrm{MWh}$ /year, respectively, with respect the solar multiplier is 1.5 . The study also concerned with the amount of emissions avoided by using CSP plants, the study estimated that, 18516.4 tons of emissions could be annually avoided by CSP plant rather than conventional plant that uses a natural gas as the energy source. The results demonstrate that, the Ber'Alganam is a good location to construct CSP plants, according to the productivity indicators.
\end{abstract}

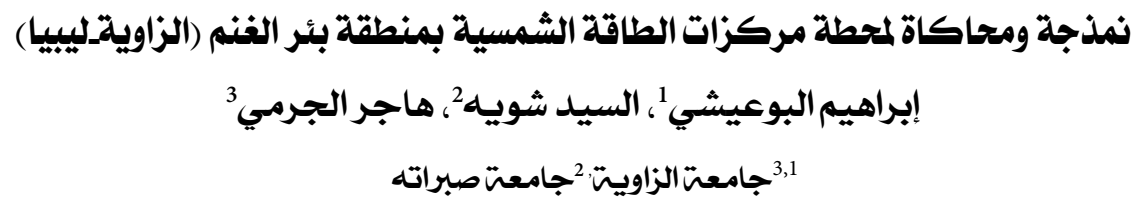

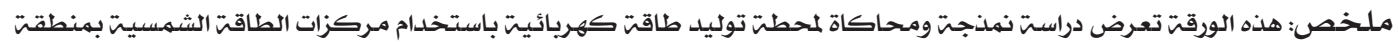

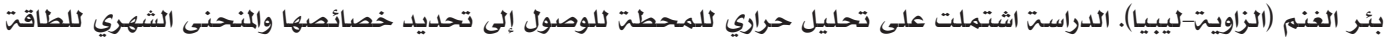




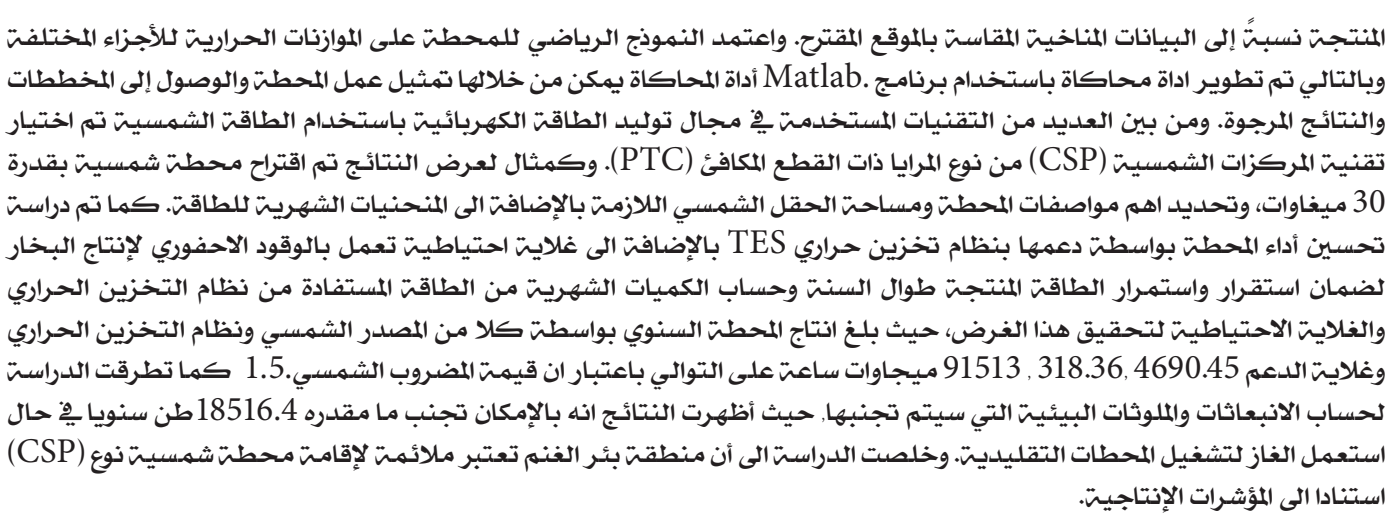

Keywords: Concentrated Solar Power, CSP, PTC, TES, fossil backup boiler.

\section{INTRODUCTION}

This paper aims to conduct modeling and simulation of a Concentrated Solar Power (CSP) Plant in Ber'Alganam area (Azzawia-Libya). The thermal analysis of the solar power plant was carried out to identify its characteristics and present the monthly power curves according to measured solar radiation and meteorological data of Ber'Alganam (Azzawia-Libya). The mathematical model of the plant was based on energy balance of each component used to develop the simulation tool using Matlab software. The simulation tool can be used to simulate the solar plant and achieve desired plots and results. Among many techniques used in the field of solar power generation, the Concentrated Solar Power (CSP) technology using Parabolic Trough Collector (PTC) or (PT) has been selected. As a sample case, a 30 MW CSP plant was proposed to present the hourly performance and productivity through entire year. The study offered a description of two more technologies; thermal energy storage (TES) and backup boiler in order to enhance and stabilize the CSP plant and the continuous production throughout daytime and estimate the amount of fuel needed for this issue, the results shows, the annual power output by both solar source, TES system, and the backup boiler are $91513,318.36$, and $4690.45 \mathrm{MWh}$ /year, respectively, with respect the solar multiplier is 1.5 . The study also concerned with the amount of emissions avoided by using CSP plants, the study estimated that, 18516.4 tons of emissions could be annually avoided by CSP plant rather than conventional plant that uses a natural gas as the energy source. The results demonstrate that, the Ber'Alganam is a good location to construct CSP plants, according to the productivity indicators.

\section{NOMENCLATURE}

$\mathrm{Q}_{\mathrm{abs}}$

DNI

$\theta$

IAM

RowShadow

EndLoss

$\eta_{\text {field }}$
Solar radiation absorbed by the receiver tubes $\left[\mathrm{W} / \mathrm{m}^{2}\right]$

Direct normal insolation $\left[\mathrm{W} / \mathrm{m}^{2}\right]$

Angle of incidence [deg]

Incidence angle modifier [-]

Performance factor that accounts for mutual shading of parallel collector rows during early morning and late evening [-]

Performance factor that accounts for losses from ends of HCEs [-]

Optical field efficiency that accounts for losses due to mirror optics and imperfections 


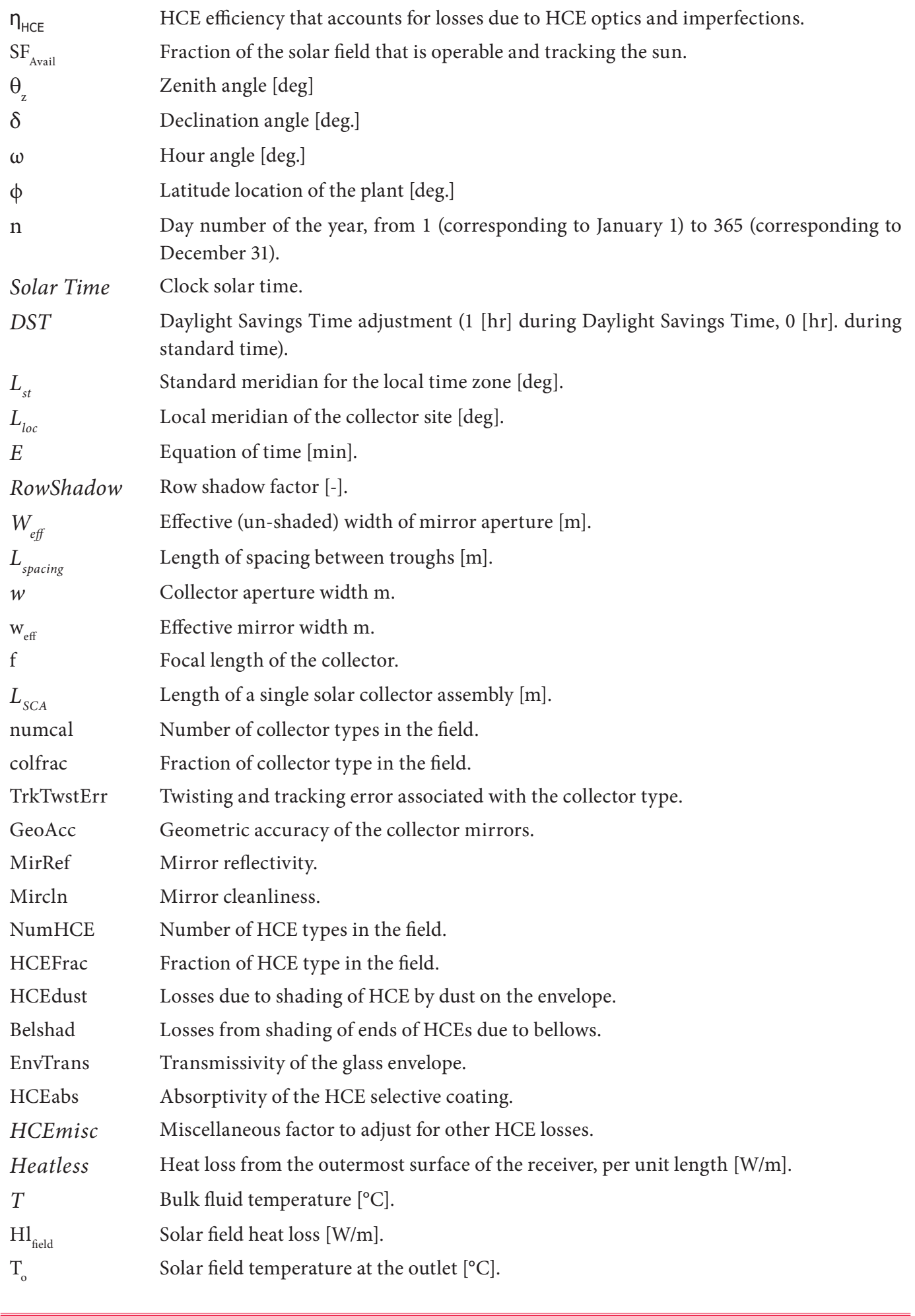


$\mathrm{T}_{\mathrm{i}}$

$\mathrm{RecHl}$

HcEfrac $_{i}$

SfpipeHl

$\Delta \mathrm{T}$

$\Delta \mathrm{h}_{\mathrm{HTF}}$

$\mathrm{N}_{\mathrm{SCA}}$

$\dot{V}_{\text {HTF }}$

$\dot{\rho}_{\text {HTF }}$

$\dot{\mathrm{m}}_{\mathrm{HTF}}$

$\Delta \mathrm{h}_{\mathrm{HTF}}$

$\eta_{\mathrm{H}}$

$\dot{\mathrm{m}}_{\mathrm{s}}$

$\Delta \mathrm{h}_{\mathrm{s}, \mathrm{Exc}}$

$\mathrm{W}_{\text {tur }}$

$\eta_{\text {tur }}$

$\dot{\mathrm{m}}_{\mathrm{s}}$

$\Delta \mathrm{h}_{\mathrm{s}, \mathrm{tur}}$

Solar field temperature at the inlet $\left[{ }^{\circ} \mathrm{C}\right]$.

Receiver heat loss $\left[\mathrm{W} / \mathrm{m}^{2}\right]$.

The fraction of HCE type in the field.

Expressed per unit area of solar field aperture $\left[\mathrm{W} / \mathrm{m}^{2}\right]$.

Difference between average field temperature and ambient air temperature $\left[{ }^{\circ} \mathrm{C}\right]$.

Change in enthalpy of the fluid from solar field inlet to solar field outlet [J/kg].

Number of solar collector assemblies in the solar field [-].

Volumetric flow rate of the HTF entering the solar field $\left[\mathrm{m}^{3} / \mathrm{s}\right]$.

HTF density at the solar field inlet, at the inlet temperature $\left[\mathrm{kg} / \mathrm{m}^{3}\right]$.

Mass flow of HTF $[\mathrm{kg} / \mathrm{s}]$.

Enthalpy difference of HTF [J/kg].

Heat exchanger efficiency.

Mass flow of steam $[\mathrm{kg} / \mathrm{s}]$.

Enthalpy difference of steam $[\mathrm{J} / \mathrm{kg}]$.

Actual power generated by turbine $[\mathrm{W}]$.

Turbine efficiency.

Mass flow of steam $[\mathrm{kg} / \mathrm{s}]$.

Enthalpy different of steam at turbine $[\mathrm{J} / \mathrm{kg}]$.

\section{INTRODUCTION}

In recent years, energy demand has increased due to the high-energy consumption in almost all fields, the world-wide consumption of energy, especially petroleum related energy, is growing steadily, and also the growth in electricity generated from renewable energy sources. The motivations of this study are to propose a solution to the electrical power failure (Blackout) in the summer season due to low quality of electrical infrastructure, which cause several injuries and casualties to citizens and negative effects on the economy. The rate of deficit in the power network was estimated at about $1650 \mathrm{MW}$ according to the report issued by General Electric Company of Libya (GECOL) in 14th July 2018). (5150 MW production and $6800 \mathrm{MW}$ consumption). Therefore, when take into account the high rates of solar radiation available in Libya; the daily average of the solar radiation on a horizontal plane in the coast region is $7.1 \mathrm{kWh} / \mathrm{m}^{2} /$ day and in the southern region is $8.1 \mathrm{kWh} / \mathrm{m}^{2} /$ day, these rates encourage investment in electricity generation by solar energy. The Concentrated Solar Power (CSP) or Concentrated Solar Thermal Power technology is one of the most favored technologies used for electricity production from solar energy which have a significant advantages in terms of power, cleanness, endless, and reliable source of energy with the capacity to entirely satisfy the present and future electricity needs. One of the first simulation model for Solar Electric Generating System plant (SEGS) was developed by Lippke [1] using EASY simulation software. The objective of the model was to simulate system behavior during part-load conditions (such as winter months and cloud-covered days). Lippke, a typical 30 MWe SEGS plant was studied using a detailed thermodynamic model. In this model, correlations for the performance of parabolic trough solar collectors were derived based on measured data under different conditions. A detailed heat transfer analysis and modelling of a parabolic trough solar receiver was carried out by Forristall [2]. One- and two-dimensional energy balances were used for short and long receivers respectively. Forristall [3], reported that, the gross HTF temperature rise across the solar field during peak summer periods is in the order of $100{ }^{\circ} \mathrm{C}$; from a cold inlet temperature of $293^{\circ} \mathrm{C}$ to a hot outlet 
temperature around $390{ }^{\circ} \mathrm{C}$ at the SEGS field, this model was used to determine the thermal performance of parabolic trough collectors under different operating conditions. Stuetzle [4, 5], investigated the thermal performance of SEGS Parabolic Trough PT plant, the analysis consisted of a dynamic model for the collector and a steady-state model for the power plant. This simulation examined the linear model predictive control strategy for maintaining the solar field at a constant outlet temperature, although maximizing the gross electricity produced was not pursued. The survey of the most popular operational solar thermal power plants worldwide was carried out [6,7], these surveys shows the largest CSP plant was installed in USA in Mojave Desert California with rated capacity of $354 \mathrm{MW}$ using parabolic through technology. This plant is the first commercial parabolic through power plant worldwide in operation for over 20 year, which indicated that the CSP plant can be classified as a long-term technique to produce electricity from the sun. IEA [8], to guarantee that the power block is effectively used during the year, the solar multiple is usually larger than unity and is typically between 1.3 and 1.4. It can be even larger (up to 2.0) if the plant has a six-hour storage system. Miguel et. al. [9], presented that, the water needed to operate the CSP plant with and without TES system are 5.07 and $5.13 \mathrm{~m} 3 / \mathrm{MWh}$ respectively. The present paper has therefore the following specific objectives:

- Conduct a feasibility study to erect the Concentrated Solar Power plant using Parabolic Trough Collector PTC with and without Thermal Energy Storage TES and backup boiler.

- Identify area of apparatus??? and area of solar field required to achieve the desired power under the meteorological data at Ber'Alganam region (Azzawia-Libya).

- Develop a Simulation tool to simulate the proposed CSP plant and to gain useful results and charts.

- Calculate the avoidable emissions by using CSP plants rather than conventional power plants.

\section{METHODOLOGY}

\subsection{System description}

The Concentrated Solar Power (CSP) Plant single configuration system is essentially a steam power plant coupled with a heat exchanger works as a boiler and the heat added to the cycle comes from a solar field, Figure (1) illustrates the flow diagram of the CSP plant.

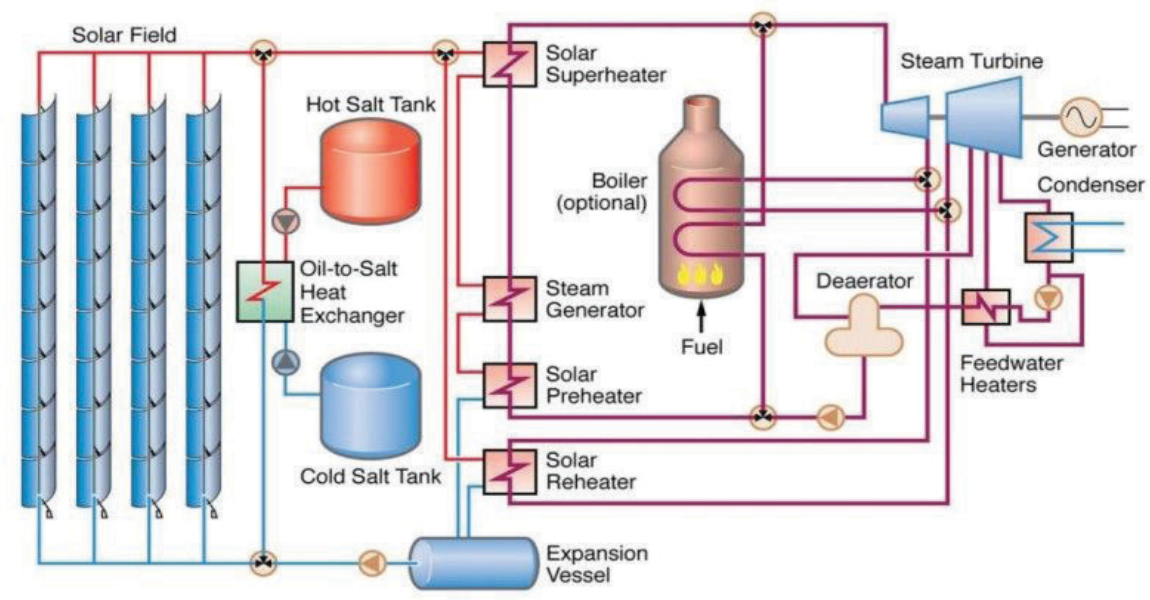

Components of a trough-type CSP plant with TES

Figure (1). diagram of the CSP plant enhanced by TES and boiler 
The CSP mainly consists of solar field, heat exchanger, steam turbine, condenser or cooling tower and feeding pumps. The sunlight incident on the parabolic reflector, is concentrated onto a focal point on the Heat Collecting Element HCE. The HTF flows in the HCE to absorb the thermal energy. Then, heat is transferred from the HTF to the water in the steam generator to produce steam. Two strategies used to enhance and support CSP plant; first, the thermal energy storage unit (TES), second, backup boiler. The TES unit allows storing the collected energy to periods where solar energy is unavailable or insufficient to operate the Rankine cycle. The backup boiler allows CSP plant to overcome any drop of solar heat and TES resourses to stable the power output throughout the year.

\subsection{CSP plant analysis}

The main equation for the instantaneous absorbed solar radiation [10]:

$$
\mathrm{Q}_{\text {abs }}=\mathrm{DNI}^{\star} \cos (\theta){ }^{\star} \mathrm{IAM}^{\star} \text { RowShadow }{ }^{\star} \text { EndLoss }{ }^{\star} \eta_{\text {field }}{ }^{\star} \eta_{\mathrm{HCE}}{ }^{\star} \text { SFAvil } \cdots
$$

The cosine of incident angle can be calculated by simple relations equations (2-4) [11]:

$$
\cos \theta=\sqrt{\cos ^{2} \theta_{z}+\cos ^{2} \delta \sin ^{2} \omega}
$$

Where:

$$
\cos \theta_{z}=\cos (\delta) \cos (\phi) \cos (\omega)+\sin (\phi) \sin (\delta)
$$

The expression for declination angle can be written as:

$$
\begin{aligned}
& \delta=23.45 * \sin \left(2 \pi \frac{284+\mathrm{n}}{365}\right) \\
& \omega=(\text { SolarTime }-12) * 15
\end{aligned}
$$

The relationship between solar time and standard time, in hours, is

$$
\text { SolaTime }=\text { S tan dardTume }- \text { DST }+\frac{\left(\mathrm{L}_{\mathrm{st}}-\mathrm{L}_{\mathrm{loc}}\right)}{15}+\mathrm{E} * \frac{1 \mathrm{~h}}{60 \mathrm{~min}} \text {. }
$$

Where E, the equation of time and can be calculated by the following correlation [12]:

$$
\mathrm{E}=229.18(0.000075+0.001868 \cos (\mathrm{B})-0.032077 \sin (\mathrm{B})-0.014615 \cos (2 \mathrm{~B})-0.04089 \sin (2 \mathrm{~B}))
$$

Where

$$
\left.\mathrm{B}=\frac{2 \pi}{365}(\mathrm{n}-1) \rightarrow \operatorname{deg}\right]
$$

The Incidence Angle Modifier (IAM) is given as an empirical fit to experimental data for a given collector type. [13]

$$
\begin{aligned}
& \text { IAM }=\frac{\mathrm{K}}{\cos (\theta)} \ldots \ldots \ldots \ldots \ldots \ldots \ldots \ldots \ldots \ldots \ldots \ldots \ldots \ldots \ldots \ldots \ldots \\
& =\cos (\theta)+0.000884(\theta)+0.00005369(\theta
\end{aligned}
$$


The row shadow factor (RowShadow) is the ratio of the effective mirror width to the actual mirror width [4].

$$
\text { RawShadow }=\frac{\mathrm{w}_{\text {eff }}}{\mathrm{w}}=\frac{\mathrm{L}_{\text {spacing }}}{\mathrm{w}} \frac{\cos \theta_{\mathrm{z}}}{\cos \theta} .
$$

The end losses are function of the focal length of the collector, the length of the collector, and the incident angle [1]:

$$
\text { EndLoss }=1-\frac{\mathrm{f} * \tan (\theta)}{\mathrm{L}_{\mathrm{SCA}}} \text {.. }
$$

The sum effect of surface and correction parameters for the collector assembly and mirrors is accounted for in the field efficiency term.:

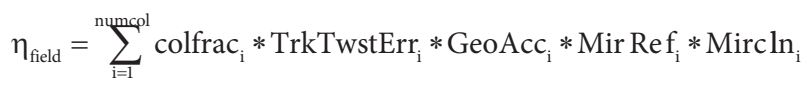

The sum effect of surface and correction parameters accounted in the HCE efficiency term, are:

$$
\eta_{\mathrm{HCE}}=\sum_{\mathrm{i}=1}^{\text {NumHCE }} \text { HCEFrac }_{\mathrm{i}} * \text { HCEdust }_{\mathrm{i}} * \text { Belshad }_{\mathrm{i}} * \text { EnvTrans }_{\mathrm{i}} * \text { HCEabs }_{\mathrm{i}} * \text { HCEmisc }_{\mathrm{i}} \cdots
$$

Typical surface properties and correction parameters for the collector field and HCE are shown in Table (1).

Table (1) typical optical parameters and correction values for solar field (LS-2 Collector type). [14] [3]

\begin{tabular}{|l|l|l|l|}
\hline Optical Properties & Value & Correction Values \\
\hline Name & 0.93 & Name & Value \\
\hline MirRef & 0.96 & HCEdust & 0.98 \\
\hline EnvTrans & 0.95 & BelShad & 0.97 \\
\hline \multirow{2}{*}{ HCEabs } & GeoAcc & 0.98 \\
\hline & MirCln & 0.95 \\
\cline { 2 - 4 } & HCEmisc & 0.96 \\
\cline { 2 - 4 } & TrkTwstErr & 0.99 \\
\cline { 2 - 4 }
\end{tabular}

The receiver heat loss from the HCE may be expressed in a single equation by applying a linear regression analysis to the calculated heat loss from the HCE per unit length of trough $[\mathrm{W} / \mathrm{m}]$ over a range of bulk fluid temperatures and DNI levels:

Heatloss $=a_{0}+a_{1} T+a_{2} T^{2}+a_{3} T^{3}+D N I\left(b_{0}+b_{1} T^{2}\right)$

Table (2) Coefficients for Receiver Heat Loss: Vacuum Annulus [10].

\begin{tabular}{|l|l|l|l|l|l|}
\hline Parameter & value & Std dev & & & \\
\hline $\mathrm{a}_{0}$ & $-9.463 \mathrm{E}+00$ & $8.463850 \mathrm{E}-01$ & & & \\
\hline $\mathrm{a}_{1}$ & $3.030 \mathrm{E}-01$ & $1.454877 \mathrm{E}-02$ & & & \\
\hline
\end{tabular}




\begin{tabular}{|l|l|l|l|l|l|}
\hline $\mathrm{a}_{2}$ & $-1.387 \mathrm{E}-03$ & $7.305717 \mathrm{E}-05$ & & & \\
\hline $\mathrm{a}_{3}$ & $6.929 \mathrm{E}-06$ & $1.070953 \mathrm{E}-07$ & & & \\
\hline $\mathrm{b}_{0}$ & $7.650 \mathrm{E}-02$ & $5.293835 \mathrm{E}-04$ & & & \\
\hline $\mathrm{b}_{1}$ & $1.129 \mathrm{E}-07$ & $6.394787 \mathrm{E}-09$ & & & \\
\hline
\end{tabular}

$H l_{\text {field }}=\frac{\int_{T_{i}}^{T_{o}} \text { Heatloss } d T}{T_{o}-T_{i}}$

$$
\mathrm{Hl}_{\text {field }}=\frac{1}{\left(\mathrm{~T}_{\mathrm{o}}-\mathrm{T}_{\mathrm{i}}\right)}\left(\begin{array}{l}
\mathrm{a}_{\mathrm{o}}\left(\mathrm{T}_{\mathrm{o}}-\mathrm{T}_{\mathrm{i}}\right)+\frac{\mathrm{a}_{1}}{2}\left(\mathrm{~T}_{\mathrm{o}}^{2}-\mathrm{T}_{\mathrm{i}}^{2}\right)+\frac{\mathrm{a}_{2}}{3}\left(\mathrm{~T}_{\mathrm{o}}^{3}-\mathrm{T}_{\mathrm{i}}^{3}\right)+\frac{\mathrm{a}_{3}}{4}\left(\mathrm{~T}_{\mathrm{o}}^{4}-\mathrm{T}_{\mathrm{i}}^{4}\right) \\
+\mathrm{DNI}\left(\mathrm{b}_{\mathrm{o}}\left(\mathrm{T}_{\mathrm{o}}-\mathrm{T}_{\mathrm{i}}\right)+\frac{\mathrm{b}_{1}}{3}\left(\mathrm{~T}_{\mathrm{o}}^{3}-\mathrm{T}_{\mathrm{i}}^{3}\right)\right)
\end{array}\right)
$$

The final term for receiver heat loss is a weighted average of the heat loss resulting from each type of HCE in the field:

$$
\mathrm{RecHl}=\sum_{\mathrm{i}=1}^{\text {NumHcॄType }} \operatorname{HcEfrac}_{\mathrm{i}} \frac{\mathrm{Hl}_{\text {field }}}{\mathrm{W}}
$$

Thermal losses from the piping leading to and from the loops in the solar field are accounted for by the following empirical equation [14]:

$$
\begin{aligned}
& \text { SfpipeHl }=0.01693 \Delta \mathrm{T}-0.0001683 \Delta \mathrm{T}^{2}+6.78 .10^{-7} \Delta \mathrm{T}^{3} \\
& \Delta \mathrm{T}=\frac{\mathrm{T}_{\text {fieldoutlet }}+\mathrm{T}_{\text {fieldinlet }}}{2}-\mathrm{T}_{\text {ambient }}
\end{aligned}
$$

Thermal losses due to piping to and from the solar field are generally small, in the order of $10\left[\mathrm{~W} / \mathrm{m}^{2}\right]$ or less during solar field operation [15].

The net energy collected by the heat transfer fluid over the field, per unit aperture area $\left[\mathrm{W} / \mathrm{m}^{2}\right]$, is the difference between the heat absorbed into the fluid by the absorber tubes and the sum of heat loss from the receivers and piping to and from the solar field that can be expressed as:

$$
\dot{\mathrm{Q}}_{\text {collected }}=\dot{\mathrm{Q}}_{\mathrm{absorbed}}-(\mathrm{RecHl}+\mathrm{SfpipeHl})
$$

The field is assumed to be operating at steady state conditions with negligible changes in potential and kinetic energy of the fluid over the course of the field. The change in the enthalpy of the heat transfer fluid can be calculated as:

$$
\begin{aligned}
& \Delta \mathrm{h}_{\mathrm{HTF}}=\frac{\dot{\mathrm{Q}}_{\text {collected }} \cdot A \cdot \mathrm{N}_{\mathrm{SCA}}}{\dot{\mathrm{V}}_{\mathrm{HTF}} \cdot \rho\left(\mathrm{T}_{\mathrm{i}}\right)} \\
& \mathrm{A}=\text { width. } \mathrm{L}_{\mathrm{SCA}} \\
& \dot{\mathrm{m}}_{\mathrm{HTF}}=\dot{\mathrm{V}}_{\mathrm{HTF}} \cdot \rho\left(\mathrm{T}_{\mathrm{i}}\right) \\
& \dot{\mathrm{Q}}_{\mathrm{HTF}}=\dot{\mathrm{m}}_{\mathrm{HTF}} \cdot \Delta \mathrm{h}_{\mathrm{HTF}} \\
& \dot{\mathrm{m}}_{\mathrm{HTF}} \cdot \Delta \mathrm{h}_{\mathrm{HTF}}=\dot{\mathrm{Q}}_{\text {coll }} \cdot \mathrm{A} \cdot \mathrm{N}
\end{aligned}
$$


The heat exchanger or steam generator works as a boiler in the Rankin cycle providing the superheated steam to operate steam turbine. The energy balance of the heat exchanger can be expressed as:

$$
\dot{\mathrm{m}}_{\mathrm{HTF}} \cdot \Delta \mathrm{h}_{\mathrm{HTF}}=\eta_{\mathrm{H}} \cdot \dot{\mathrm{m}}_{\mathrm{s}} \cdot \Delta \mathrm{h}_{\mathrm{s}, \text { Exc }}
$$

A simple mathematical relation needed to express the performance of the steam turbine can be written as:

$$
\mathrm{W}_{\mathrm{tur}}=\eta_{\mathrm{tur}} \cdot \dot{\mathrm{m}}_{\mathrm{s}} \cdot \Delta \mathrm{h}_{\mathrm{s}, \mathrm{tur}}
$$

The critical component of the power cycle is the cooling technology to be integrated in a CSP plant to condensate the exhaust steam from the turbine. In this stage, the two strategy may consider for proposal plant. First technology is a Water-Cooled Condenser (WCC), second is Air-Cooled Condenser (ACC). The Once-through cooling system is a type of WCC which supplied by lack from prospective ALNAHAR network which is planned to passed through the area of project as shows in Figure 2 [16].

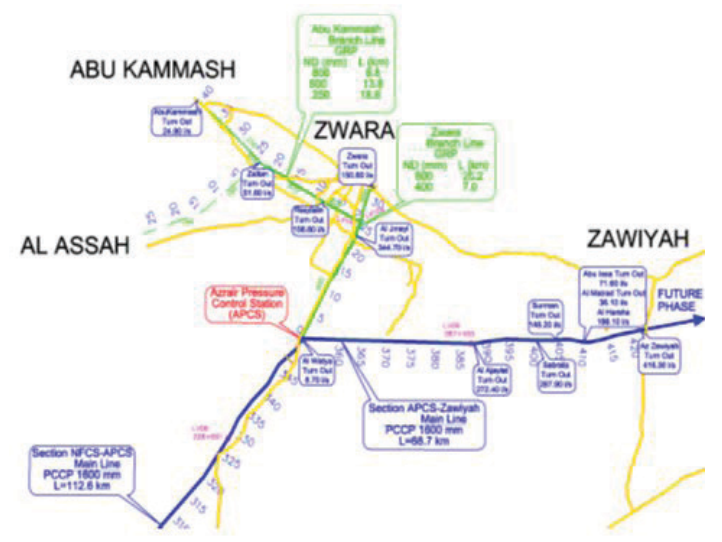

Figure (2) Water network of ALNAHAR [16]

Second strategy is ACC technology developed to meet these needs, while having some disadvantages, but the ACC systems make it possible to build a power station in locations where there are insufficient water supply resources, often the case of PTC stations, there are two types of ACC systems are distinguished in (a) direct ACC systems and (b) indirect ACC systems [17].

The proposed CSP plant accomplished by TES system, a major classification of TES systems is Sensible heat Thermal Energy Storage (STES) and Latent heat Thermal Energy Storage LTES. For a widely used in CSP plants, in this study, the LTES was selected as a Thermal Energy Storage system.

The model was programmed by Matlab software Package and submitted as a GUI which makes it easy to use. The flowchart of mathematical model is presented in Figure 3.

\section{RESULTS AND DISCUSSION}

The primary results are the estimation of the areas of solar field required to achieve nominal power under conditions of all months, evaluate the performance parameters of the $30 \mathrm{MW}$ CSP plant and consider the effect of adding TES and the fossil fuel boiler to the CSP plant. Figure 4 shows the results of present model vs. to some real CSP projects with and without TES where a same trend was observed. 
Figure 5 presents the Area of solar field vs. Power output at noonday for different months with and without thermal heat storage TES. The figure shows the area required for solar field is varying depending upon the time of year on which the solar plant is designed; in the summer season (August) where the DNI measured was in highest level, the field area required was minimum, while in the winter season (December), much more area of solar field is needed.

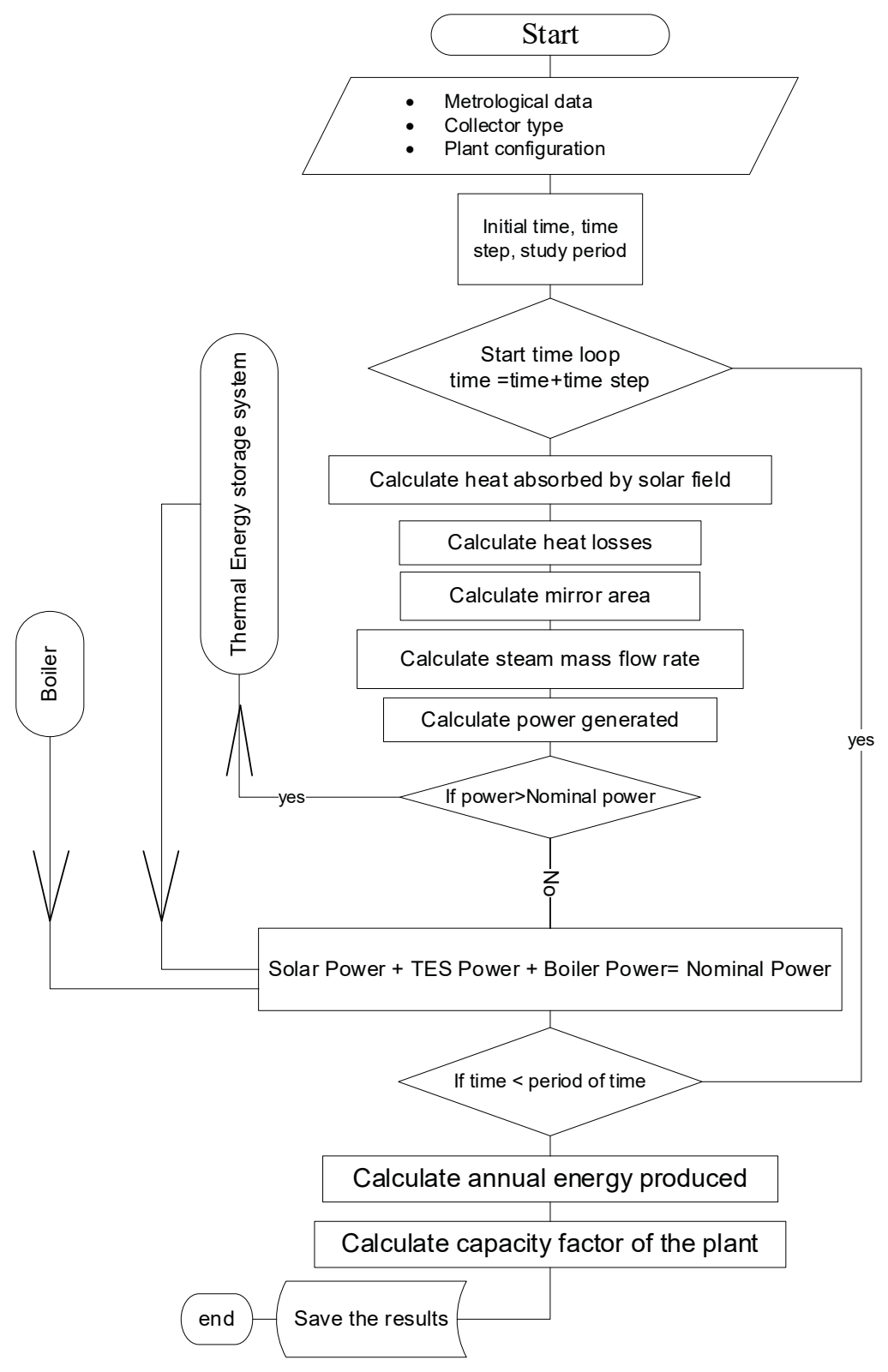

Figure (3) flowchart of the present model 


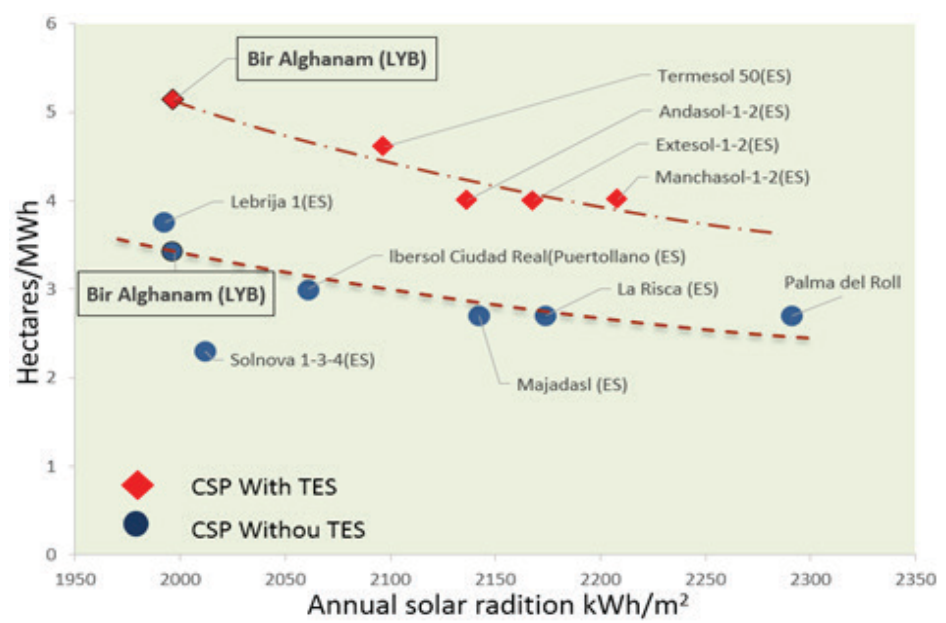

Figure (4). solar field area per MWh of current model existing vs. real CSP projects in the reviewed literature
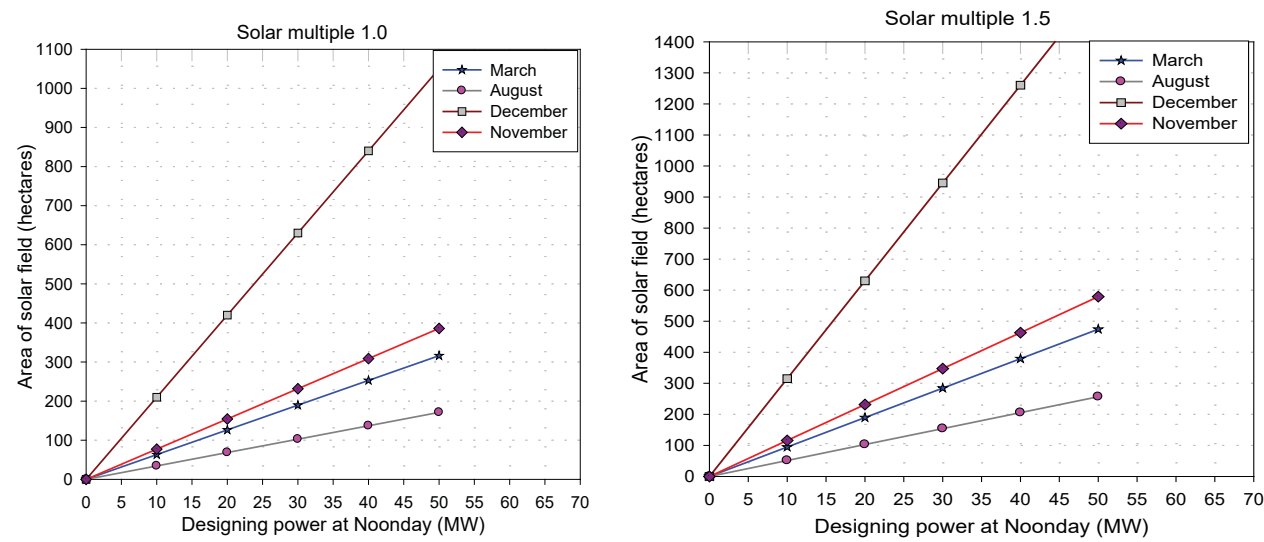

Figure (5) solar field area vs. designing power based on midday condition of different months

For a sample case of $30 \mathrm{MW}$ the solar field area needed for the design of CSP plant under noontime of all months are tabulated in Table (3). The table also include the ratio of area of solar field per unit power (1 MW), and the minimal area of solar field needed to achieve the nominal power of CSP plant under midday of August conditions.

Table (3) solar field area under conditions of all months

\begin{tabular}{|c|c|c|c|c|}
\hline \multirow[b]{2}{*}{ Month } & \multicolumn{2}{|c|}{ Without TES (Solar multiple 1) } & \multicolumn{2}{|c|}{ With TES (Solar multiple 1.5) } \\
\hline & $\begin{array}{l}\text { Solar field area } \\
\text { (Hectares) }\end{array}$ & Hectares/MWh & $\begin{array}{c}\text { Solar field area } \\
\text { (Hectares) }\end{array}$ & Hectares/MWh \\
\hline January & 212.9 & 7.1 & 319.4 & 10.6 \\
\hline February & 243.5 & 8.1 & 365.3 & 12.2 \\
\hline
\end{tabular}




\begin{tabular}{|l|l|l|l|l|}
\hline \hline & & & & 284.6 \\
\hline March & 189.7 & 6.3 & 216.9 & 9.5 \\
\hline April & 144.6 & 4.8 & 182.7 & 6.1 \\
\hline May & 121.8 & 4.1 & 176.6 & 5.9 \\
\hline June & 117.7 & 3.9 & 159.6 & 5.3 \\
\hline July & 106.4 & 3.5 & 154.1 & 5.1 \\
\hline August & 102.7 & 3.4 & 200.1 & 6.7 \\
\hline September & 133.4 & 4.4 & 323.6 & 10.8 \\
\hline October & 215.7 & 7.2 & 347.4 & 11.6 \\
\hline November & 231.6 & 7.7 & 945.3 & 31.5 \\
\hline December & 630.2 & 21.0 & & \\
\hline
\end{tabular}

Figure 6 shows the comparison between the capacity factors $\mathrm{C}_{\mathrm{f}}$ of proposed CSP plant with and without thermal energy storage. In summer season [August], the $\mathrm{C}_{\mathrm{f}}$ between $0.23-0.3$ for plants without TES. Addition six hours TES system will increases capacity factors between 0.34-0.46. Figure 6 also shows, the capacity factor lies beyond unity if design CSP plant under December condition, then the solar field will give energy more than needed, as a result December not suitable choosing as a design month.

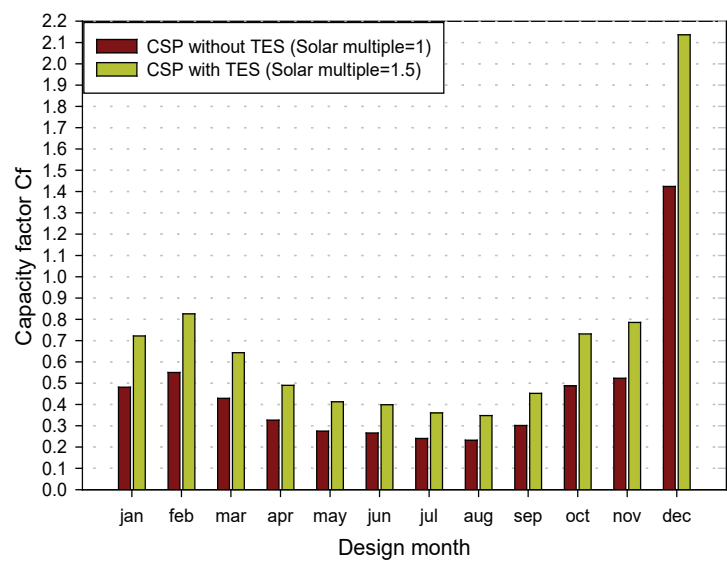

Figure (6) Capacity factor of PTC plant with and without TES.

Figure 7 presents the monthly power curve of CSP during the daytime with and without TES system and the amount of energy required to support the plant by backup boiler. Also Figure 7 shows, for a solar multiple equal to 1.5, the thermal energy storage system operate between April to September.

The monthly energy stored is presented in Figure (8) for limiting values of solar multiple 1.5-2. Figure 8 shows the highest value of energy stored in August were $230 \mathrm{MWh}$ for solar multiple 2 and $110 \mathrm{MWh}$ for solar multiple 1.5.

Figure 9 show the backup boiler supplement as a third energy source of the plant, which adding the energy after dissipate the energy of TES system, the highest amount of energy needed to support the CSP plant by boiler was found in December which reaches $650 \mathrm{MWh}$. In addition, the figures from (7) to (9) present the plant with interactive three sources of energy; solar energy, thermal energy storage and backup boiler energy, all together guarantees a consistent power output throughout the year. 


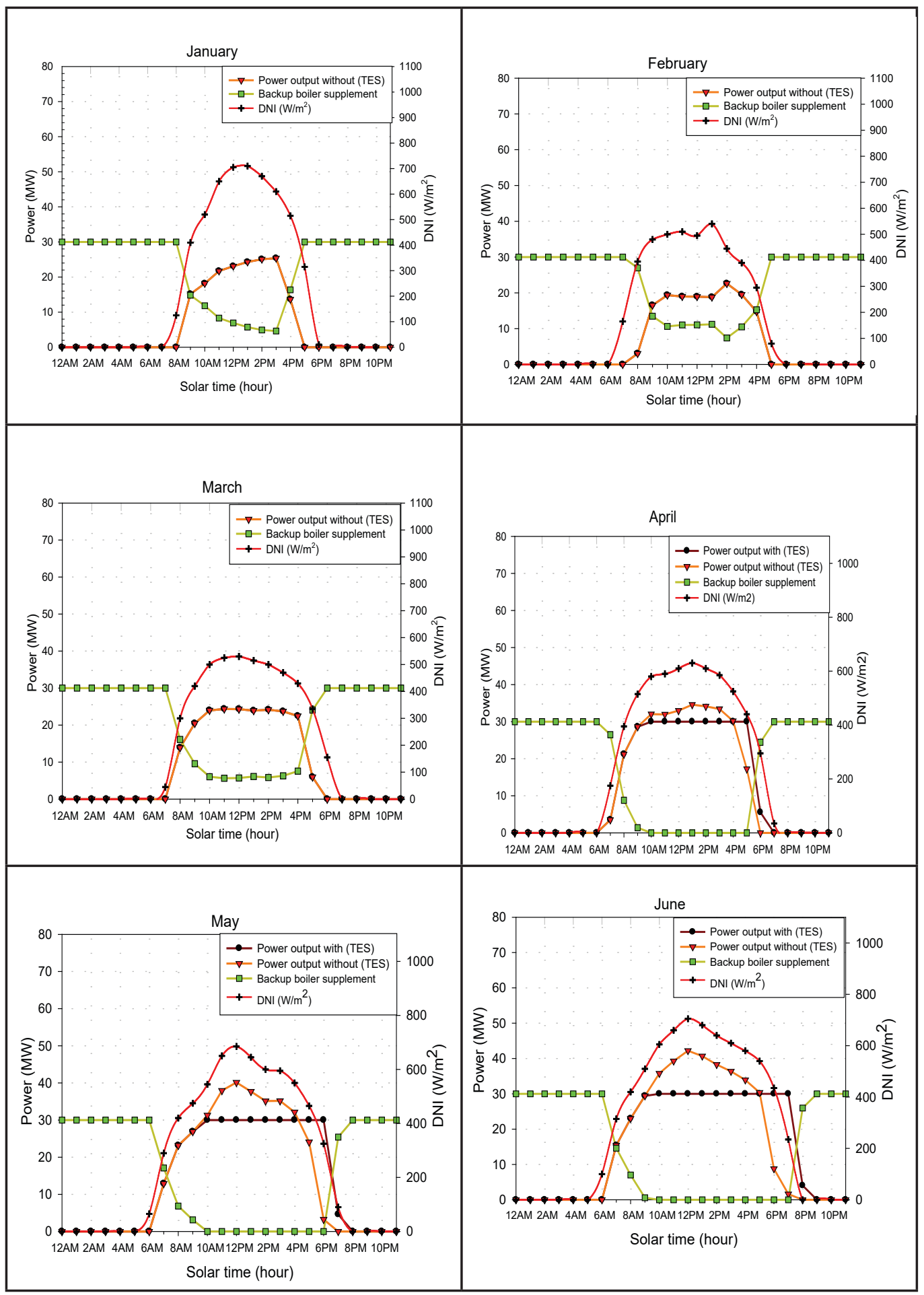



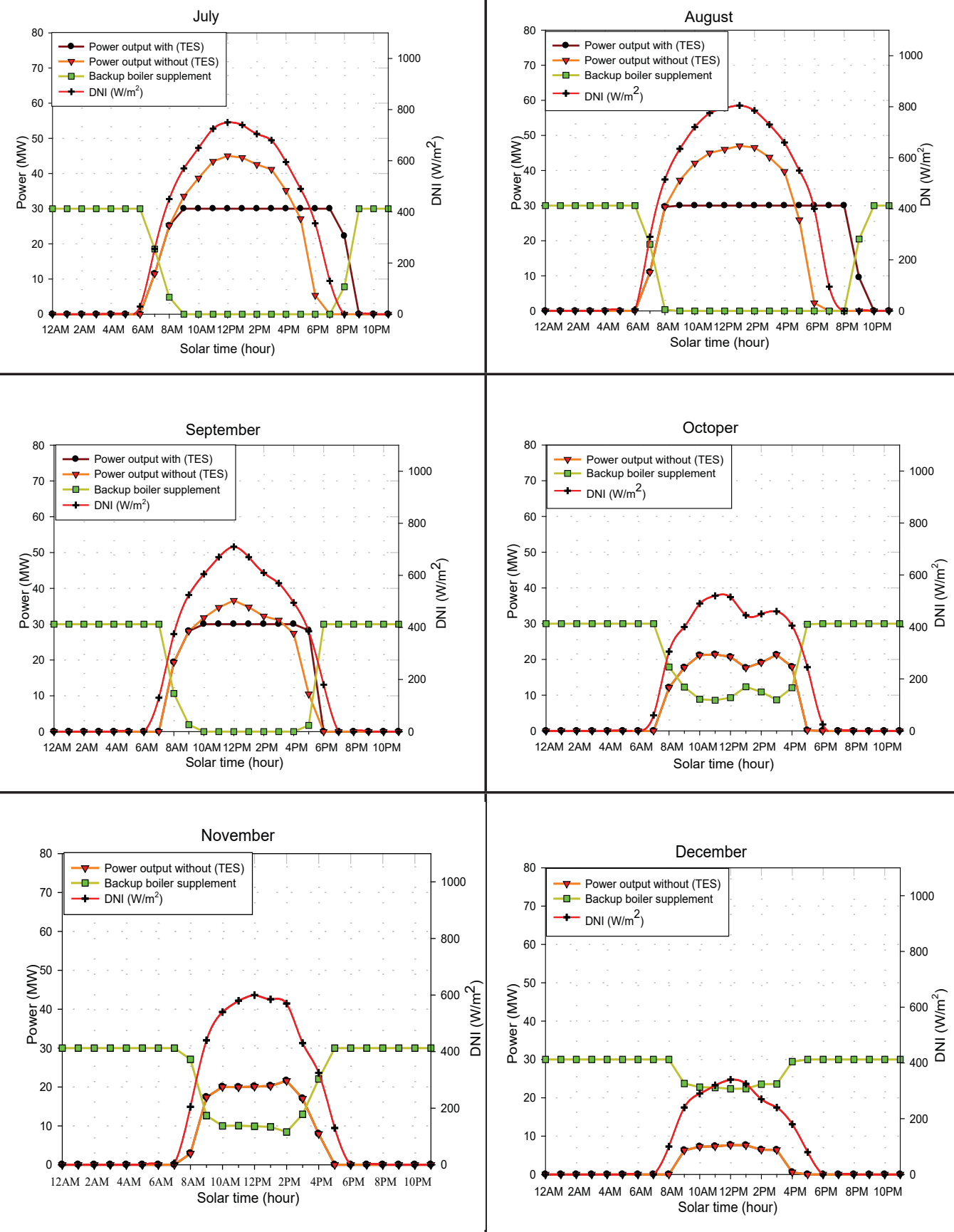

Figure (7) Monthly power curve with and without TES and support power by boiler with solar multiple=1.5

One of many features of solar power plants is a decreasing the environmental pollution; they contribute 
directly to reduce the emissions from conventional power plants. From the above, the annual power generated by the solar source of $30 \mathrm{MW}$ CSP plant is $91513 \mathrm{MWh} /$ year and the capacity factor is 0.3482 (design at Aug., Plant with TES, solar multiple=1.5). Then water consumption can be estimated as $\left(91513 \mathrm{MWh} /\right.$ year $^{\star} 5.07$ $\mathrm{m}^{3} / \mathrm{MWh}=463,971 \mathrm{~m}^{3} /$ year). According to IEA [18], the amount of carbon dioxide emissions per $\mathrm{kWh}$ from electricity generation depends on the net calorific value of fuel. In table (4), the emissions reduction potential were calculated using Emission Intensity (E I) of natural gas and fuel oil which are used in the conventional plant [19]. The amount of emissions can be calculated as:

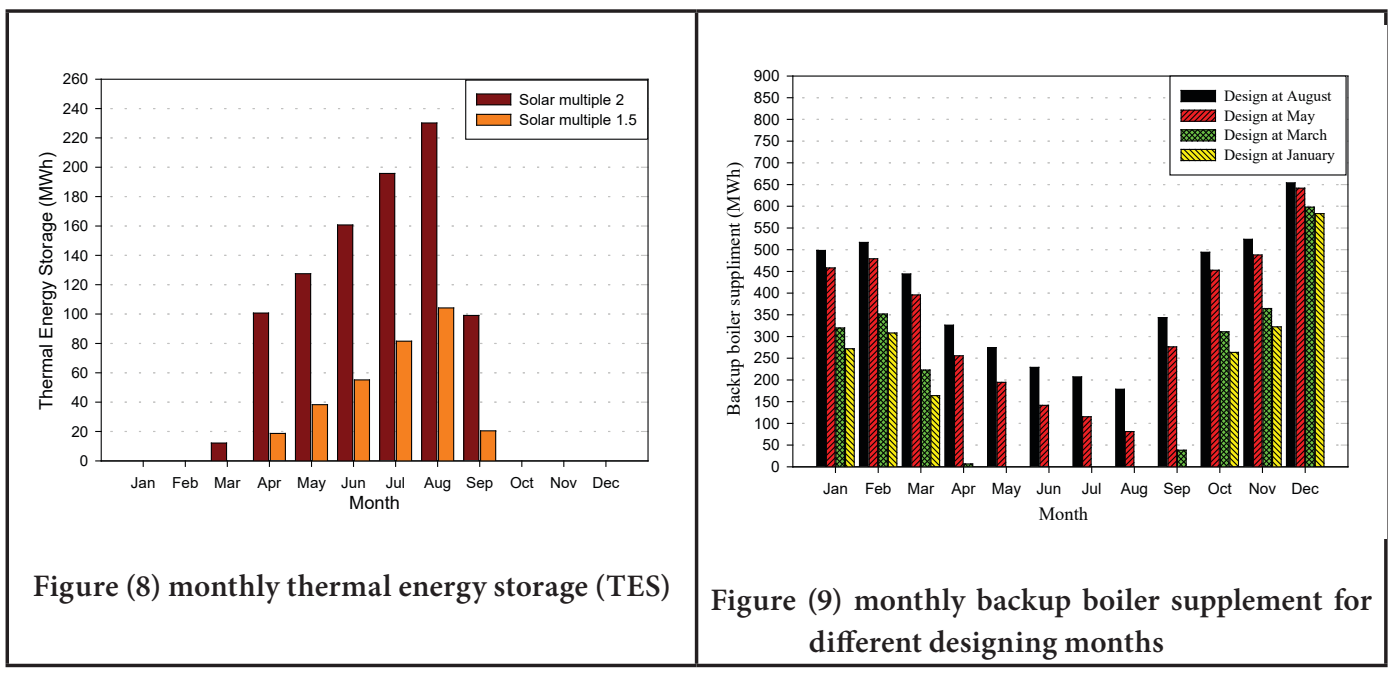

Table (4) Emission reduction potential [18], [19]

\begin{tabular}{|c|c|c|c|c|}
\hline \multirow[b]{2}{*}{ Pollutant } & \multicolumn{2}{|c|}{ Emission Intensity (g/GJ) } & \multicolumn{2}{|c|}{ Emission (ton) } \\
\hline & Natural gas & Fuel oil & Natural gas & Fuel oil \\
\hline $\mathrm{CO}_{2}$ & 56,100 & 77,400 & 18480.7 & 25497.5 \\
\hline $\mathrm{NO}_{x}$ & 93.3 & 195 & 30.7 & 64.2 \\
\hline Sox & 0.68 & 1,350 & 0.2 & 444.7 \\
\hline $\mathrm{CO}$ & 14.5 & 15.7 & 4.8 & 5.2 \\
\hline \multicolumn{3}{|c|}{ Total emissions ton/year } & 18516.4 & 26011.6 \\
\hline
\end{tabular}

Table (5) summarizes the main characteristics of a standalone 30-MW CSP plant. The data is compared against the same plant incorporating thermal energy storage (TES) and also including energy input from backup boiler.

Table (5) main characteristics of a $30 \mathrm{MW}$ CSP plant with different configurations

\begin{tabular}{|l|l|l|l|}
\hline characteristic & Basic CSP & CSP with TES & $\begin{array}{l}\text { CSP with TES with } \\
\text { backup boiler }\end{array}$ \\
\hline Nominal Power generation (Mwe) & 30 & 30 \\
\hline
\end{tabular}




\begin{tabular}{|c|c|c|c|}
\hline Solar multiple & 1 & \multicolumn{2}{|l|}{1.5} \\
\hline Collector type & \multicolumn{3}{|l|}{ LS-2 } \\
\hline Number of Solar collectors & 218 & \multicolumn{2}{|l|}{327} \\
\hline Space between rows $(\mathrm{m})$ & \multicolumn{3}{|l|}{13.5} \\
\hline Width of collector (m) & \multicolumn{3}{|l|}{5} \\
\hline Length of solar collector $(\mathrm{m})$ & \multicolumn{3}{|l|}{47.1} \\
\hline Number of collectors in loop & \multicolumn{3}{|l|}{8} \\
\hline Apparatus area (Hectares) & 41.1 & \multicolumn{2}{|l|}{61.6} \\
\hline Solar field area (Hectares) & 102.7 & \multicolumn{2}{|c|}{154.0746} \\
\hline Capacity factor $\%$ & 23.22 & 34.82 & 100 \\
\hline Full load equivalent (hours/year) & 2,034 & 3,050 & 8760 \\
\hline Annual electric generation (MWh/year) & 61,020 & 91,513 & 262,800 \\
\hline Water use (m3/year) & 313032.6 & \multicolumn{2}{|c|}{463,971} \\
\hline Water required (m3/MWh) & 5.13 & \multicolumn{2}{|l|}{5.07} \\
\hline Total emissions avoided (ton/year) & 18516.4 & \multicolumn{2}{|c|}{26011.6} \\
\hline \multirow{3}{*}{ TES system } & Extent & \multicolumn{2}{|c|}{6 hours } \\
\hline & media & \multicolumn{2}{|c|}{ Latent Heat Thermal Storage (LHTS) } \\
\hline & material & \multicolumn{2}{|c|}{$(\mathrm{NaNO} 360 \%+\mathrm{KNO} 340 \%)$} \\
\hline
\end{tabular}

\section{CONCLUSION}

This paper presents the evaluation study of CSP plant for Ber'Alganam (Azzawia), Libya. The performance of a CSP plant is greatly affected by the solar field area identification and enhancement technologies. A variety of technologies are commercially available and could be used in CSP plants; TES unit and backup boiler. In the present study, a mathematical model was developed, the results compare well with present CSP projects and the same trend were found. The present model gives a good simulation of CSP plant. A 30 MW CSP plant were considered as a sample case for the simulation of the proposed CSP plant. The analysis identify solar multiples 1, 1.5 and 2, collector type LS-2, and 6 hours TES system. The valuable findings of the study are summarized as follows:

- The design conditions of CSP plant in a midday of August and the solar field area per unit load were found to be 3.4 and 5.1 Hectares/MWh for solar multiple 1 and 1.5 respectively.

- A 30 MW CSP supported by TES unit and backup boiler was proposed as a sample case with solar multiple 1.5 and the results presented agrees well with those for simple CSP configuration (without TES and backup boiler).

- For the proposed plant, the TES unit will operate between April to September.

- An increase in solar multiple increased energy production, and the capacity factor.

- The incorporation of TES results in a significant increase in the capacity factor of the plant $(34.82 \%$, compared to $23.22 \%$ in the simple configuration), which results in higher operation capacity $(3,050 \mathrm{~h}$, compared to 2,034 h without TES) and yearly power generation (91,513 MWh/year, compared to 61,020 $\mathrm{MWh} /$ year).

- The performance of CSP plants improved with the addition of a fossil fuel backup boiler. 
- The annual energy stored in TES is $926.13,318.36$ for solar multiple 2 and 1.5.

- The annual amount of supported energy from backup boiler is 4690.45, 3979.89, 2212.8, 1913.08 MWh/ year when design plant at Aug, May, Mar. and Jan. respectively.

- The annual amount of emissions which can be avoided by using proposed plant rather than conventional plant are 18516.4, 26011.6 tons when using Natural gas and fuel oil respectively.

Finally, according to the good production levels and were the capacity factors in the reasonable ranges, the study can confidently conclude the possibility of establishing the CSP plant in Ber' Alganam area. To extend this study, the economic feasibility of the proposed CSP plant is recommended to identify LCOE and NPV.

\section{REFERENCES}

[1]. Lippke, F., "Simulation of the part-load behavior of a 30Mwe SEGS plant", Tech.rep. SAND-95-1293, Sandia National Labs., Albuquerque, NM (United States), 1995.

[2]. Forristall, R., "Heat Transfer Analysis and Modeling of a Parabolic Trough Solar Receiver Implemented in Engineering Equation Solver”. National Renewable Energy Laboratory (NREL), Colorado, 2003.

[3]. Forristall, R. "Heat Transfer Analysis and Modeling of a Parabolic Trough Solar Receiver Implemented in Engineering Equation Solver." National Renewable Energy Laboratory, NREL/TP-550-34169, October 2003.

[4]. Stuetzle, T., “Automatic control of the 30 Mwe SEGS VI parabolic trough plant”, Master's thesis, University of WisconsinMadison, College of Engineering, 2002.

[5]. Stuetzle, T., Blair, N., Mitchell, J., and Beckman, W., "Automatic control of a 30 MWe SEGS VI parabolic trough plant". Solar energy, 76(1-3), pp. 187-193. 225, 2004.

[6]. GDP growth rate 2009, February 2011, http://data.worldbank.org/indicator.

[7]. Solar Energy Generating Systems, 26 November 2010. <www.wikipedia.org >

[8]. IRENA, “Concentrating Solar Power", Volume 1: Power Sector, Issue 2/5, 2012.

[9]. Miguel G. S., Corona B., Servert J., Lopez D., Cerrajero E., Gutierrez F. and, Lasheras M.," Technical and Environmental Analysis of Parabolic Trough Concentrating Solar Power (CSP) Technologies", The Handbook of Environmental Chemistry 34, ISBN 978-3-319-17099-2, DOI 10.1007/978-3-319-17100-5, Springer International Publishing Switzerland 2016.

[10]. Patnode, A. M., “Simulation and Performance Evaluation of Parabolic Trough Solar Power Plants”, 2006.

[11]. Duffie, John A., and Beckman, William A. Solar Engineering of Thermal Processes. $2^{\text {nd }}$ edition. New York: John Wiley and Sons, Inc., 1991.

[12]. Iqbal, M., “An Introduction to Solar Radiation”, Ontario: Academic Press Canada, 1983.

[13]. [13] Dudley, V., Kolb, G. J., Mahoney, A. R., Mancini, T. R., Matthews, C. W., Sloan, M., and Kearney, D., “Test Results: SEGS LS-2 Solar Collector. Sandia National Laboratories", SAND94-1884, December 1994.

[14]. [Price, Henry (Microsoft Excel program). Excelergy. Last updated 2005.

[15]. Channiwala S.A. and Ekbote A.," A Generalized Model to Estimate Field Size for Solar-Only Parabolic Trough Plant", SASEC2015 Third Southern African Solar Energy Conference 11 - 13 May 2015.

[16]. ILF consulting Engineering, Great Man-Made River Project," Gadames-Zwara-Az Zawiyah Water system, Contract No. 40115-A-530-00-CT-CT-1001.

[17]. Poullikkas A., Kourtis G., Hadjipaschalis I. An overview of CSP cooling systems. Proceedings of the 3rd International Conference on Renewable Energy Sources \& Energy Effciency, May 2011, Nicosia, Cyprus.

[18]. International Energy Agency (IEA), “CO2 emissions from fuel combustion”, Edition 2012.

[19]. Air pollution from electricity-generating large combustion plants (PDF), Copenhagen: European Environment Agency (EEA), 2008, ISBN 978-92-9167-355-1, archived from the original on 16 July 2011. 